\title{
Palliative Care and Hospice
}

\begin{abstract}
Moderator:
Hasan Shanawani, MD

Assistant Professor

Wayne State University School of Medicine

Detroit, Michigan
\end{abstract}

Panelists:

Frederick A. Smith, MD, FACP

Long Island Jewish Medical Center (LIJMC)

Lake Success, New York

North Shore University Hospital

Manhasset, New York

Tanveer Mir, MD, MACP

Associate Chief, Geriatrics and Palliative Medicine

Long Island Jewish Medical Center

North Shore-Long Island Jewish Health System

New York, New York

Mary Lahaj, MA,

Clinical Pastoral Education (CPE) Certified

Chaplain, Groton School

Groton, Massachusetts

Are Physicians Ethically Obligated to Address Hospice as an Alternative to 'Usual' Treatment of Advancing End-Stage Disease?

Article DOI: http://dx.doi.org/10.5915/43-3-9209

Video DOI: http://dx.doi.org/10.5915/43-3-9209V

Frederick A. Smith, MD, FACP

\section{Abstract:}

Hospice care is ideally suited to meet the psychosocial and spiritual needs of dying patients, providing the opportunity to settle financial, property, and inheritance issues; to mend lacerations in important lifetime relationships, including forgiving and asking forgiveness; and to assure a degree of

Correspondence should be directed to

Frederick A. Smith, MD, FACP

fsfasmith@gmail.com autonomous control over the environment and the social and spiritual processes that attend one's death. Physicians are not only imprecise in prognosticating a patient's time to die, they tend to be overoptimistic in their predictions. A "no" answer to the question, "Would I be surprised if this patient died in the next year?" is a reasonable starting-point for discussing hospice care as a potential treatment plan, now or in the future. Physicians have a duty to present palliative care in hospice as an alternative to the recurrent hospital interventions that are typical in the last six to 12 months of life tor patients who are failing and have declining prospects for one-year survival.

Key words: Palliative care, hospice, end-stage disease, informed consent, end of life.

Hospice care is a wonderful resource that is underutilized in our society. I aim to make the case that physicians should be introducing the hospice option much earlier to the patient who is receiving disease-controlling treatment but is on the declining arc of the disease trajectory.

When I speak to health-care providers about palliative care, I often ask my listeners to identify three conditions they associate with dying well and three conditions they associate with dying badly (Table). I find that the good and the bad conditions usually mirror each other. First, people do not want to die in pain or with other severe physical symptoms. If pain can be well controlled only in the hospital, they would rather die in the hospital. Second, however, most people say if symptoms can be controlled at home, they would prefer to die at home than in the hospital. When I ask doctors, they tell me that they see the hospital intensive care unite (ICU) as a particularly bad place to die. Third, people tell me that they want their loved ones nearby when they die, a condition that seems harder to ensure if they die in a hospital.

Nevertheless, although most Americans die of chronic diseases ${ }^{1}$ characterized by a phase of decline rather than from sudden unexpected catastrophes, 
Table. Informal polls of health-care providers regarding good death versus bad death.

Condition

Location

Symptom Management

Access to loved ones
Symptoms not controlled

Bad Death

Hospital

Sporadic or restricted visits

by loved ones; dying alone

\section{Good Death}

Home

Symptoms controlled, preferably at home * If symptoms not controlled at home, then controlled in hospital

Around-the-clock access and presence until moment of death (in comfortable, unrestricted environment - i.e. home) more than $40 \%$ still die in the hospital. ${ }^{2}$ Too many patients still fail to have their pain or shortness of breath adequately alleviated, even in an acute care setting, ${ }^{3}$ and we see too many die alone.

Let me identify some explicit observations and assumptions (admittedly anecdotal) derived from 25 years as a primary care internist and five years as a full-time palliativist. First, in my experience, it is rare for a patient or family to report that hospice is anything but a positive experience. ${ }^{4}$ Second, when doctors propose modern death-delaying medical interventions to a patient who is approaching the end of his life, most do not address hospice as an alternative at all. When physicians do suggest hospice, the suggestion often comes so late that the dying patient is bedbound and disoriented 5 and unable to truly enjoy being in the home environment from which he has derived so much of his experience of meaning and love and security.

Even when an individual has written out an advance directive that explicitly affirms the primacy of comfort at end-of-life and defines goals that are compatible with hospice, this wish too often remains unfulfilled. ${ }^{6}$ The patient with such an advance directive depends on the expertise of his doctor to recognize when the time has come to switch from remittive to palliative care. When the man with end-stage congestive heart failure (CHF) is going home after his penultimate hospital admission, the doctor does not tell him: "The next time you are hospitalized, I will have to try an intravenous dobutamine infusion in the coronary care unit (CCU), although I do not think it will work. By then you will be too short of breath to walk or even talk much, and you will have to decide whether you want ventilator support. Maybe this is the time to go home with hospice support. I think you might have a good month or two."

What is the ethical value that the doctor has neglected when he or she discharges this patient with terminal CHF but fails to tell him that death may be only weeks away? The doctor has forgotten that patient autonomy depends, for its proper function, on informed consent, and this lapse betrays a lack of respect for the autonomy of the patient, especially one who has specified end-of-life wishes in an advance directive. ${ }^{7}$ Under the doctrine of informed consent, the physician has a duty to fully inform the patient about the likely consequences of any clinical decision that affects his health and well-being. In addition to describing the nature and hoped-for benefit of the next treatment and its risk, the doctor is supposed to tell the patient about the alternative to this treatment, 8 in this case, palliative and hospice care. In this domain, the patient is not the expert; the doctor is. The patient depends on the doctor to tell him that the benefit of remittive treatment is so low, and its likely futility and potential risk are so significant, that this is now the time to change course to an alternative treatment that will focus on comfort and quality of life for the days that remain.

The change from death-forestalling treatment to hospice care does not mean giving up care. Instead, it means changing to a different kind of care. Palliative and hospice providers have robust medical expertise in preventing or alleviating symptoms whether they are pain, dyspnea, nausea, delirium, anxiety, constipation, or all of these. Besides providing special equipment that is given to improve func- 
tion at home and 20 hours a week custodial assistance from an aide, hospice also provides social work, nutritional, spiritual, and other support to uninsured as well as insured patients. Unlike typical home care, hospice nurses do not leave after a couple of weeks. They are there for the duration and visit at least once weekly. They are always accessible by pager to talk to the patient and the home caregivers through any acute crisis, often advising about the use of medications that have been placed in the home for such events. ${ }^{9}$ If symptoms cannot be controlled at home, our Hospice Care Network on Long Island, like many other hospice organizations, has inpatient facilities where patients can be admitted to fine-tune palliative medications before returning home. ${ }^{10}$ In 2009, 21\% of hospice patients died in hospice inpatient facilities, and $10 \%$ in acute care hospitals (presumably under the care of palliativists). The other $69 \%$ died in residential settings, $40 \%$ in private homes and $29 \%$ in nursing homes or other residential facilities. ${ }^{4}$

The key criteria for admission to hospice is the presence of a life-limiting disease that is believed to limit the patient's survival to six or fewer months and the patient's decision to forgo further aggressive interventions that aim for a cure or long-term remission. ${ }^{7}$ It is to be noted that contrary to the belief of many health providers, a patient does not to have to consent to do not resuscitate (DNR) status in order to to receive home hospice care. The goal of hospice care is to maximize the relief of suffering and dysphoric symptoms and to foster as much as possible a sense of emotional, social, and spiritual well-being. Being in hospice does not mean one has to give up all intravenous treatments such as antibiotics or red cell transfusions if it is believed these will help the patient feel better.

In my view, when a patient's death appears certain, even if months away, hospice should be seen as usual care rather than the exception. ${ }^{10}$ If this is so, how would we describe the alternative to hospice care? The alternative would be the pattern we see too often now, an accelerated pattern of rehospitalizations coupled with declining patient function. On each hospitalization, aggressive interventions are applied to extend life and restore function, each time with less success. The interventions may add to the patient's burden as he submits to hospital procedures and experiences adverse effects from medica- tions and procedures. When rehospitalization replaces hospice as the treatment option, it becomes increasingly likely that the patient will die in an ICU, perhaps attached to a mechanical ventilator and on multiple intravenous medications that artificially maintain blood pressure. If the patient is not sedated on a ventilator in the ICU, it is likely that pain, dyspnea and other symptoms are not optimally controlled and the loved ones who visit may focus more on the latest numbers or radiologic images rather than on holding the patient's hand. The patient is much less likely than in home hospice to exchange meaningful good-byes with his family before he dies.

What else is lost when aggressive hospital treatment is usual care at the end of life? When patients know they are going to die, they often express an intent to use their remaining time to get things in order. These things may be in part legal and financial, but they are just as likely relational and spiritual. Ira Byock, a pioneer in palliative care at Dartmouth Medical Center, has written about "The Four Things That Matter Most" at end of life. These are four sentences that loved ones want to say to each other when death is certain for one of them: "Please forgive me," "I forgive you," "Thank you," and "I love you." 11

The six-month period for hospice care originally envisioned when Medicare created the benefit and subsequently imitated by private insurers allows ample time for frayed or broken relationships to be mended and restored. When the patient actually has six months to prepare for death - a substantial period of time when he is still mentally competent and able to move about - he is granted an experience of dignity, autonomy, and mastery that may be absent when he passively submits to treatments with little chance of success and participates in the death-defying, death-denying drama that doctors, patients, and families so often engage in, always avoiding the " $d$ " word. In contrast, facing the inevitable and intentionally adopting the hospice option gives a person with life-limiting disease some control over where he will die and how he will die and a much greater capacity to determine the social and spiritual conditions and processes that he wishes to attend his death.

The hospice movement has had growing visibility in recent years, and enrollment has been increasing. Forty percent of all deaths reportedly now occur 
in hospice. In contrast to the early years of hospice, more enrollees have nonmalignant diseases than cancer. In 2009, 40\% of hospice patients had cancer, and $60 \%$ had noncancer diagnoses. However, the national median length of stay (LOS) in hospice is still only three weeks, and one-third of hospice enrollees experience its benefit for fewer than seven days. ${ }^{4}$ I am told that the median LOS on Long Island hospice is only 17 days. When a patient dies within days after discharge from the hospital, his time at home is probably characterized by a high degree of physical dependence and a rapid descent into stupor and coma; in fact, the decision to enter hospice has usually been made by a surrogate, not by the patient. ${ }^{5} \mathrm{~A}$ short period of hospice care after hospitalization means the decision to discharge a patient has often been made too late for the patient to consciously experience the autonomous benefits possible when time at home has truly been long enough to put things in order, although the change in environment and goals can be very meaningful and beneficial to family members.

Despite the increased use of hospice, we must remember that more than $40 \%$ of all Americans still die in the hospital, and about $20 \%$ of Americans die in an ICU. ${ }^{12}$ Why do so many patients with end-stage disease fail to benefit from hospice? Clearly, patients or families may resist recognizing that death is imminent until the evidence is overwhelming. Abundant literature exists about the reluctance of oncologists to discuss prognosis with cancer patients ${ }^{13-5}$ despite evidence that patients want realistic and explicit information about prognosis. ${ }^{16}$ Doctors are trained to intervene to save and prolong life and often lack training in how to approach transition to hospice. It is possible that some specialists see a patient's death as a professional failure or they may be reluctant to end their relationship with the patient and to see a palliativist become the main provider of medical care. ${ }^{17}$ When a patient relapses after a period of stable management, the reflexive habit of an oncologist, cardiologist, or pulmonary specialist is usually to offer a new, alternative treatment, perhaps even one that has been reported to have some success, even if it is "off-label." It is natural for a patient or family member to grasp at any hope the doctor may offer, without fully appreciating the likelihood of success or of adverse effects. Specialists often seem to find it difficult to discuss directly the likely futility in such treatments and the probability of death, sometimes explicitly asserting that they do not want to take away hope. ${ }^{18}$ As mentioned already, specialists seldom discuss hospice care as an alternative to continued active treatment, even when a patient has previously drafted an advance directive requesting palliative care in just this hopeless situation. ${ }^{19}$

Before the advent of effective modern therapeutics, physicians' main task after diagnosing a life-limiting disease was to add a prognosis for survival and then support the patient through the time remaining. Nowadays, doctors are less skillful at prognosticating, and, as new therapeutics are constantly introduced, predicting survival accurately is not easy, especially for periods greater than one month. ${ }^{20}$ Studies have also shown that specialists tend to be over-optimistic about their patients' survival. One study found that oncologists, on average, predicted the cancer patients they were treating to live three to five times longer than they actually did. Reduced accuracy in predicting survival was correlated with a longer relationship with the patient. ${ }^{21}$

Nevertheless, prognostication is not an impossible task. Useful algorithms such as the Palliative Prognostic Index (PPI) ${ }^{22}$ and the Palliative Prognostic (PaP) Score ${ }^{23,24}$ can help an oncologist predict which patients will probably survive for less than four to six weeks, possibly enough time to get some autonomous benefit from hospice. One, however, does not need a mathematical formula to read the writing on the wall. The patient who is ill from cancer, dementia or severe disease of the heart, lungs, kidneys or liver and is being rehospitalized with increasing frequency is almost certainly on the declining arc of life. Increasing weakness, loss of appetite, weight loss, shortness of breath, and markers of malnutrition also point to the "end-game." If specialists take the time to reflect, they can recognize that the patient's descending spiral has begun or is accelerating. It has been suggested that the physicians caring for fragile patients might remind themselves about prognosis and quality of dying if they were to periodically ask: "Would I be surprised if my patient died within 12 months?"25,26 If the answer is "No" - and we have noted doctors' excessive optimism in overestimating survival - I would suggest that now is the time to discuss hospice as an alternative to remittive treatments, not fleetingly, 
but with the same thoroughness and seriousness as they would apply to a treatment they think might keep death at bay.

How, then, can we help more patients increase the time they participate in hospice's generous sixmonth benefit and thus enjoy greater potential for autonomous preparation for death and enjoyment of the time that is left? In my view, one of the most important changes would be for specialists who treat life-limiting diseases to encourage and guide the patient, at the time of diagnosis, to begin diseasespecific preparation for the inevitable end of life, including preferences for changing from remittive to palliative or hospice care. Such planning is especially needed when the patient may survive only one to two years, but it should not be ruled out even when survival could be five to 10 years. Certainly, when a patient with previously stable disease decompensates and begins to decline in function and requires hospital care with increasing frequency, it is another time to encourage the patient to initiate an advance directive or to review one already in place and to think about hospice. ${ }^{27}$

It is a well-established bioethical norm that respect for autonomy means that the patient must receive informed consent about any treatment with physician disclosure not limited to the treatment's nature, benefits, and risks but also including information about the alternative to the proposed treatment. ${ }^{6}$ The legal standard is that the patient should be provided with all information that a "reasonable person" would wish in deciding whether to follow the physician's advice. ${ }^{28}$ It seems to me that, if one takes the "bird's-eye view" of the reasonable person, the patient with life-limiting disease should be adequately informed about the benefits (and risks) of hospice as an alternative approach to remittent treatment.

Assuming that bird's-eye view, one could frame the question differently: What is the alternative to hospice care when one's health is declining towards death? The alternative I too often see is sometimes humiliating discomfort and sometimes new physical insults resulting from recurring hospitalizations, worsening function when one is at home, and few resources to assist the patient outside the hospital. If death and hospice care are avoided to the bitter end, there is an increasing probability that the patient will spend his last days delirious and in an ICU, ${ }^{31}$ pos- sibly intubated and sedated to unconsciousness, while receiving antibiotics, pressors and other cardiovascular support through multiple vascular access sites that increase the risk of nosocomial infection or peripheral gangrene. On a regular ward, without intervention from a palliative care specialist, the patient is likely to be receiving suboptimal treatment of pain, delirium, anxiety, constipation, or symptoms of intestinal obstruction. Meantime, instead of focusing on the "four last things" Byock writes about ${ }^{11}$ the patient's loved ones may be preoccupied by reports from the doctors about the patient's latest vital signs, oxygen saturation, serum creatinine level or the radiologist's interpretation of the lung infiltrate on the current bedside chest Xray.

If patients do not understand how imminent death is and do not enter hospice with enough time left to take autonomous actions, they may lose the opportunity to settle issues related to finances, property, and power of attorney; to safeguard dignity and autonomy by staying in their own home environment rather than redonning a hospital gown and being transported to and from tests and therapeutic interventions; and to exert some control over their dying process. Do they wish to stay alive by prolonging the dying process while delirious in the hospital, or would they rather die at home, even if their days are somewhat shortened? Do they want to maximize the number of loved ones around them at the end and the time they spend with them? Do they want loved ones to read the holy scripture of their tradition and pray at their bedside during their last hours and days? If they wish the latter conditions to accompany dying, they are far more likely to experience them in home hospice than during active treatment in the hospital.

For the religious person, dying while pursuing aggressive life-prolonging interventions may mean loss of spiritual care. Questions that may seem even more important than the ones above may include: Have I made things right with God? Will I die while a loved one whispers a prayer or a sentence from scripture in my ear? For all humans, who are animals with uniquely spiritual concerns, even when they are atheists, the following may be important concerns: Have I forgiven or asked forgiveness? Have I repaired a feud or reconciled a loved one? Have I expressed my love and gratitude? Will a loved one 
hold my hand at the last minute?

Can those of us who are physicians say that we are completing our duty to our patients if we fail to advise those with life-limiting illness about the ultimate outcome and their need to prepare for it? Are we helping them towards the complete preparation many of them would want - spiritual and familial, as well as financial and physical - if we do not inform them fully about hospice or if we only tell the family at the very, very end when the patient lacks capacity and clearly has only hours or days to live?

Most of us want our own doctors to provide us and those we love with this kind of large-picture informed consent. All religions contain some form of what Christians call the Golden Rule: "So in everything, do to others what you would have them do to you, for this sums up the Law and the Prophets." ${ }_{30}$ The Jewish Talmud counsels: "What is hateful to you do not do to your fellowman. This is the entire Law; all the rest is commentary." ${ }^{11}$ Prophet Muhammad allughele is reported to have asserted: "No one of you is a believer until he desires for his brother that which he desires for hims elf." ${ }^{2}$ Similar injunctions are found in Confucianism, 33 Buddhism and Hinduism. ${ }^{34}$ If we as physicians want the option of palliative care for ourselves, and if we want our own doctors to tell us when it is time to avail ourselves of hospice as death nears in our own last illness, how can we neglect to provide our patients with the same opportunity?

I believe it is always good for doctors to reflect on their own mortality and eventual death. Saint Benedict, the early Christian monastic leader, advised his monks "to keep death daily before your eyes." ${ }_{35}$ For each of us who is religiously observant especially those of us who are "people of the book" it may be valuable to ask: What words from my faith would I like to hear before I die? Will the Jewish doctor have the chance to repeat the Vidui?

Unto You, O Lord my God and God of my ancestors, I acknowledge that my life and recovery depend upon You. May it be Your will to heal me. Yet, if You have decreed that I shall die of this affliction, may my death atone for all sins and transgressions which I have committed before You. Shelter me in the shadow of Your wings; grant me a share in the world-to-come. Protector of orphans and Guardian of widows, protect my beloved family, with whose soul my own soul is bound. Into Your hand I commit my soul. You have redeemed me, O Lord God of truth. Shema Yisrael, Adonai Eloheinu, Adonai Echad, Hear O Israel: the Lord is our God, the Lord alone. Adonai hu haElohim. Adonai hu haElohim. The Lord is God. The Lord is God. ${ }^{36}$

Will I, a Christian, have someone assuage my anxiety with these words?

For the perishable must clothe itself with the imperishable and the mortal with immortality. When the perishable has been clothed with the imperishable, and the mortal with immortality, then the saying that is written will come true: 'Death has been swallowed up in victory. Where, $O$ death is your victory? Where, $O$ death is your sting?' ... But thanks be to God! He gives us the victory through our Lord Jesus Christ. ${ }^{37}$

Will you, my distinguished physicians rooted in Islam, be comforted by a last reminder of your beginning and your end?

To Allah we belong, and to Him is our return. ${ }^{38}$

Everyone shall taste death. And only on the day of resurrection shall you be paid your wages in full. And whoever is removed away from the fire and admitted to paradise, this person is indeed successful. The life of this world is only the enjoyment of deception. ${ }^{39}$

When the angels take the lives of the righteous, the angels say to them: 'Salaamun Alikum, enter paradise, because of the good deeds that you used to do.' 40

Will someone recite to you the shahada?

I bear witness that there is no god but Allah, and Muhammad is His messenger." 41

For all human beings - all mortal, all patients at the end, whether or not honored with the title "doc- 
tor," whether or not identifying with religious faith - who can deny that there is a profound need at the end to complete the circle of relationship? Is not home hospice more likely than the hospital to facilitate a final opportunity to say those 12 words that matter most?

I love you.

I forgive you.

Please forgive me.

Thank you. ${ }^{11}$

\section{References}

1. Kung HC, Hoyert DL, Xu JQ, et al. Deaths: final data for 2005. Natl Vital Stat Rep. 2008;56(10):1-124. http://www.cdc.gov/nchs/data/nvsr/nvsr56/nvsr5 6 10.pdf

2. Flory J, Young-Xu Y, Gurol I,et al. Place of death: U.S. trends since 1980. Health Affairs. 2004:194-200. http://dx.doi.org/10.1377/hlthaff.23.3.194

3. Tranmer JE, Heyland D, Dudgeon D, et al. Measuring the symptom experience of seriously ill cancer and noncancer hospitalized patients near the end of life with the memorial symptom assessment scale. J Pain Symptom Management. 2003:420-9. http://dx.doi.org/10.1016/S0885-3924(03)00074-5

4. NHPCO Facts and Figures: Hospice Care in America. Alexandria, VA: National Hospice and Palliative Care Organization; 2010. http://www.nhpco.org/files/public/Statistics Rese arch/Hospice Facts Figures Oct-2010.pdf [Accessed 2011 Nov 17]

5. Silveira MJ, Kim SYH, Langa, KM. Advance directives and outcomes of surrogate decision making before death. N Engl J Med. 2010;362:1211-8. http://dx.doi.org/10.1056/NEJMsa0907901

6. A Controlled Trial to Improve Care for Seriously III Hospitalized Patients: The Study to Understand Prognoses and Preferences for Outcomes and Risks of Treatments (SUPPORT). JAMA. 1995:274:1591-8. http://dx.doi.org/10.1001/jama.274.20.1591

7. Kinlaw K. Ethical issue in palliative care. Sem Onc Nurs. 2005;21:63-8. http://doi.org/hfs

8. Cardinal JS, Gunderman RB, Tarver RD. Informing patients about risks and benefits of radiology examinations: a review article. J Am Coll Radiol. 2011;8:402-

8. http://dx.doi.org/10.1016/j.jacr.2010.09.007

9. Centers for Medicare \& Medicaid Services. Medicare hospice benefits. Baltimore, Maryland:
Centers for Medicare \& Medicaid Services; 2011. http://www.medicare.gov/publications/pubs/pdf/0 2154.pdf [Updated 2011-Aug; Accessed 2011 Nov 19] 10. Campbell ML. When will "usual care" in advanced illness be "palliative care"? J Palliat Med. 2010;13:934-5. http://doi.org/hfp

11. Byock I. The four things that matter most: a book about living. New York: Free Press (Simon \& Schuster); 2004.

12. Flory J, et al. Place of death: U.S. trends since 1980. Health Affairs. 2004;23:194-200. http://dx.doi.org/10.1377/hlthaff.23.3.194

13. Gordon EJ, Daugherty CK. 'Hitting you over the head': oncologists' disclosure of prognosis to advanced cancer patients. Bioethics. 2003;17:142-68. http://dx.doi.org/10.1111/1467-8519.00330

14. Lamont EB, Christakis NA. Prognostic disclosure to patients with cancer near the end of life. Ann Intern Med. 2001;134:1096-105. PubMed PMID: 11412049

15. Daugherty CK, Hlubocky FJ. What are terminally ill cancer patients told about their expected deaths? A study of cancer physicians' self-reports of prognosis disclosure. J Clin Oncol. 2008;36:5988-93. http://dx.doi.org/10.1200/JCO.2008.17.2221

16. Hagerty RG, Butow PN, Ellis PM. Communicating with realism and hope: Incurable cancer patients' views on the disclosure of prognosis. J Clin Oncol. 2005;23:1278-88. http://doi.org/hfa

17. McGorty EK, Bornstein BH. Barriers to physicians' decisions to discuss hospice: insights gained from the United States hospice model. J Eval Clin Prac. 2003;9:363-72. http://doi.org/hfr

18. Caugherty CK, Steensma DP. Overcoming obstacles to hospice care: An ethical examination of inertia and inaction. J Clin Oncol, 2003; 21(Suppl):42s-45s. http://dx.doi.org/10.1200/JC0.2003.01.167

19. KE, Fuller JD, Yaffe K, et al. Communication and decision-making in seriously ill patients: Findings of the SUPPORT project. The Study to Understand Prognoses and Preferences for Outcomes and Risks of Treatments. J Am Geriatr Soc. 2000;48:S187-93. PubMed PMID: 10809474

20. Galre PA, Sinclair CT. Palliative medicine review: prognostication. Journal of Palliat Med. 2008;11:84103. http://dx.doi.org/10.1089/jpm.2008.9992

21.Christakis NA, Lamont EB. Extent and determinants of error in doctors' prognoses in terminally ill patients: prospective cohort study. BMJ. 2000 Feb 
19;320(7233):469-72. http://doi.org/hft

22. Morita T, Tsunoda J, Inoue $S$, et al. Survival prediction of terminally ill cancer patients by clinical symptoms: Development of a simple indicator. Clin Oncol. 1999;29:156-9.

23. Pirovano $\mathrm{M}$, et al. A new palliative prognostic score: a first step for the staging of terminal ill cancer patients. J Pain Symptom Management. 1999;117:231-9.http://doi.org/hfv

24. Tarumi Y, Watanabe SM, Lau F, et al. Evaluation of the Palliative Prognostic Score (PaP) and Routinely Collected Clinical Data in prognostication of survival for patients referred to a palliative care consultation service in an acute care hospital. J Pain Symptom Management. 2011;42:419-31. http://doi.org/hf4

25. Pattison M, Romer AL. Improving care through the end of life: launching a primary care clinic-based program. Palliat Med. 2001;249-54. http://dx.doi.org/10.1089/109662101750290335

26. Moss AH, Lunney JR, Culp S. Prognostic significance of the "surprise" question in cancer patients. J Palliat Med. 2010;13:837-40.http://doi.org/hfx

27. Quill TE. Perspectives on care at the close of life. Initiating end-of-life discussions with seriously ill patients: Addressing the "elephant in the room." JAMA. 2000;284:2502-7. http://doi.org/hfz

28. Meisel A, Kuczewski M. Legal and ethical myths about informed consent. Arch Intern Med, 1996;156:2521-6. http://pubmed.gov/8951294

29. Rady MY, Johnson DJ. Admission to intensive care unit at the end-of-life: is it an informed decison? J Palliat Med. 2004;18:705-11.http://doi.org/hf3

30. Matthew 7:12. biblegateway.com

31. Talmud, tracate Shabbat 31a; Midrash Avot de Rabbi Natan. http://en.wikipedia.org/wiki/Jewish ethics

32. Forty Hadiths of an-Nawawi. http://www. 40hadith.com/40hadith en.htm

33.

Analects

$12: 2$.

http://www.ibiblio.org/chinesehistory/contents/08 fea/c02files.02lib/text001.html

34. Udanavarga 5:18 (Buddhist); Mahabharata 5.1517 (Hindu). http://www.edminterfaithcentre.ca/ goldrule.htm

35. Rule of St. Benedict, Chapter 4: "The instruments of good works," 48. http://www.ewtn.com/library/ PRIESTS/BENRULE.HTM

36. Blumenthal D. A spiritual guide for the Jewish patient. In: Gary GR. Voices in our midst: spiritual resources. Atlanta: Scholars Press; 1996:37-40.

http://www.js.emory.edu/BLUMENTHAL/JewishPat ient.html

37. I Corinthians15:53-57. New International Version 1984.

38. The Glorious Qur'an, Chapter 2, Verse156.

39. The Glorious Qur'an, Chapter 3, Verse 185.

40. The Glorious Qur'an, Chapter 16, Verse 32.

41. The declaration of faith - the first pillar of Islam:

http://www.islamic-dictionary.com/5-pillarsfaith.php

\section{Question from the audience}

Patients on Medicare who are hospitalized are allowed six weeks only. After that the patient has to be discharged. How long are patients allowed to remain in hospice before they are discharged? Where do they go after hospice?

Dr. Smith's response: This is where hospice is different from the hospital. Actually, an inset in one of the slides shows that when you go home from the hospital you sometimes have a visiting nurse or a nurse aid. That does not continue for long, usually for a couple of weeks in my experience. On the other hand, as long as you meet the criteria, you stay in hospice. You have a nurse aide four hours a day, five days a week; you have a nurse visiting you regularly; you have someone available to you 24 hours a day, seven days a week to call if you are in a crisis; and you have medicines in the house to use if you are in crisis so you can avoid going to the emergency room. You can have morphine, ativan, or whatever else you may need. In general, hospice is for people who have been certified that they have six or months or less to live. The truth is, if you are at six months and they think maybe you have another month or two to live, nobody kicks you out. That is not the goal. Rarely, patients will get discharged from hospice. One situation might be when a patient's name suddenly comes up on the liver transplant list. The patient may get the liver transplant and actually survive. Another situation might be that the patient may become too stable for Medicare criteria. This may be a problem for some people who need a lot of help and to those who cannot afford nursing homes much of the time. This is, by the way, a problem with tube feeding because, again, unless you are Medicaid eligible, you may have to pay yourself. For instance, dementia 
would be one situation. Sometimes we have people go in with dementia who are not eating much. We think they are going to die within the six months, and they end up being very stable. Sometimes those people do have to be discharged from hospice early. They could always come back. It is not like rehabilitation days or physical therapy days; there is no limit.

Hospice is the most generous insurance benefit in America. Most private insurance companies will pay for this service. Actually, private insurance is often more generous than Medicare because it tends to be oriented towards younger people whom they do not expect will use it as much. People who are of working age and are not on Medicare can often go into inpatient hospice for a fairly long period of time, and it will be covered. Unfortunately, with Medicare you usually have to be at home, but they can bring you into an inpatient setting. In Long Island we have four places right now in the hospice care network where people can come in, sometimes to die, if they are very sick and it is very hard to take care of them at home. Sometimes they come in to get over some symptoms and then go back home. It is a wonderful benefit, and you can see I am a preacher for it. One thing I always say in palliative care is that it is not a one-way conveyor belt, and there is no steel door that slams shut and you cannot get out. You can get out. We find in our palliative care units that some people improve considerably because we are doing so much less to them, and we get them out of the ICU. Someone in hepatic coma may get back to consciousness. If they are on too many drugs, we withdraw some drugs, and they wake up. They usually still go into hospice but often we have restored a level of function that is a gift to them and to their family, at least for a short period of time.

\section{Question from the audience}

What will be the role of the prior care-giving team, to which the patient is so accustomed, once a transition has been made to hospice?

Dr. Smith's response: The primary physician can continue to be the supervising physician. I have to tell you that it is hard for these folks to make house calls, but when I was in general medicine, I almost always remained the supervising physician, and once or twice I made a house call. Sometimes Dr. Mir or someone at hospice would make the house call if that was necessary. I did call in the orders, and I would take messages from the family. Sometimes a spouse would insist they wanted antibiotics for the fever, and we would work it out even though we were not sure that they were going to be helpful. Therefore, primary physicians can remain involved to the extent that they want to be and they can continue to be the supervising physician and bill for it. 